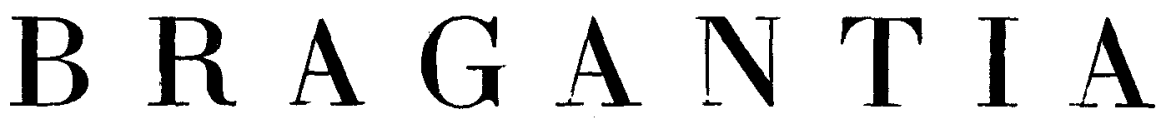

Boletim Cientifico do Instituto Agronômico do Estado de S. Paulo

Vol. 28

Campinas, julho de 1969

N. ${ }^{\circ} 20$

\title{
DETERMINAÇÃO ESPECTROFOTOMÉTRICA DE CÁLCIO EM SOLOS ( $\left.{ }^{1}\right)$
}

Fernando A. Soares Coelfo e Hermano Gargantini, engenheiros-agrônomos, Seção de Fertilidade do Solo, Instituto Agronômico

\section{SINOPSE}

É apresentado estudo da determinação de cálcio em extratos de solo por espectrofotometria de chama, utilizando o espectrofotômetro Beckman, modêlo DU.

A composição da chama, as pressões dos gases, as interferências e os métodos para eliminá-las foram estudados.

Verificou-se ser imprescindivel a eliminação das interferências causadas pelos ions de aluminio, ferro e fosfato nas concentrações que normalmente ocorrem nos solos.

A utilização de EDTA a pH 9 apresentou resultados satisfatórios na eliminação dessas interferências quando em concentração 0,01 M na solução em que foi determinado o cálcio.

\section{1 - INTRODUÇÃO}

A determinação espectrofotométrica de cálcio em extratos de solos e outros materiais tem sido prèviamente estudada $(1,2,3,11,20,23,24)$, sendo constatada a necessidade de eliminação de interferências de determinados íons.

A emissão do cálcio em chama é fortemente influenciada por alguns anions, como fosfato e sulfato $(1,10,18,25)$, e por catíons como alumínio e ferro $(2,3,10,11,18,20)$.

As técnicas propostas para eliminar as interferências são as mais diversas, envolvendo processo de separação (6), troca iônica (18) e técnicas de extração $(5,9)$, as quais exigem muita

( $\left.{ }^{1}\right)$ Recebido para publicação em 20 de janeiro de 1969. 
manipulação das amostras, podendo ocorrer perdas parciais e contaminações que introduzem erros no método analítico, além de muito demoradas, impossibilitando a sua utilização em laboratórios, onde grande número de amostras de solo são analisadas.

Foster e Hume (12), para eliminação de interferências, utilizam a técnica de padrão interno, enquanto Pietzka e Chun (21) indicam a adição de grande excesso das espécies interferentes às soluçōes padrões e às amostras.

Lott e outros (19), em determinação espectrofotométrica de cálcio em digeridos de fôlhas de café, utilizam a técnica de adição dos ions interferentes em padrões, em concentrações equivalentes às encontradas nos digeridos, para eliminação das interferências. Entretanto, Gallo (13, 14, 15, 16 e 17) tem adotado a nuesma curva de calibração para culturas diversas, onde os teores de potássio variaram de $0,35 \%$ a $12,72 \%$, de magnésio entre $0,10 \%$ e $0,66 \%$ e de fósforo entre $0,030 \%$ e $0,862 \%$ sôbre a matéria sêca, tendo sido tomados como referência os teores médios encontrados em fôlhas de café, ou seja, 2,5\%, $0,375 \%$ e $0,125 \%$, respectivamente para potássio, magnésio e fósforo.

Os processos mencionados para eliminação das interferências apresentam a desvantagem de que a exatidão e a sensibilidade podem ser baixadas, e, em alguns casos, a composição exata da amostra e a natureza das interações devem ser conhecidas.

David (8) reduziu ao mínimo o efeito das interferências, usando a técnica de adição de substância química que reage preferencialmente com a espécie interferente, durante o processo de evaporação.

Wirtschafter (26) conclui, em seu trabalho, que o uso de EDTA na solução do catíon metálico a ser analisado fornece resultados satisfatórios na eliminação e redução de interferências por anions, complexando o metal a ser determinado por espectrofotometria de chama, sendo o complexo destruído na chama, livre de interferências.

West e Cooke (25), em suas pesquisas, mostraram que a adição de solução de EDTA pH 9 na solução de cálcio a ser analisada, de modo a fornecer concentração $0,1 \mathrm{M}$ em EDTA, foi Eficiente na eliminação de interferências dos aníons sulfato e fosfato, reduzindo sensivelmente o efeito interferente do cation 
FERNANDO A. SOARES COELHO \& HERMANO GARGANTINI

alumínio. Citam, ainda, que o mecanismo do efeito depressivo é provocado pelo arrastamento de sais de cálcio, no óxido de alumínio refratário de chama.

Cobjetivo do presente trabalho é a determinação de métodos de eliminação de interferências, na determinação espectrofotométrica do ion cálcio, em extratos de solo.

\section{2 - MATERIAL E MÉTODO}

\section{1 - REAGENTES}

Solução de EDTA 0,5 M a pH 9,0: Pesar 93,0630 g do sal dissódico do ácido etilenodiaminotetroacético, dissolver em solução de hidróxido de sódio $1 \mathrm{~N}$, em balão de $500 \mathrm{ml}$. Diluir com água destilada até aproximadamente $450 \mathrm{ml}$ e acertar o pH da solução a 9,0, com solução concentrada de hidróxido de sódio, e completar o volume. Deixar em repouso até o dia seguinte e filtrar.

Solução padrão de cálcio $0,1000 \mathrm{~N}$ : colocar carbonato de cálcio p.a., em pó, na estufa a $105^{\circ} \mathrm{C}$ por 6 horas, aproximadamente. Esfriar em dessecador e pesar $5,0040 \mathrm{~g} \mathrm{em}$ copo de $50 \mathrm{ml}$. Adicionar ácido clorídrico $(1+1)$, pouco a pouco, até dissolver todo o carbonato de cálcio. Transferir para erlenmeyer de $500 \mathrm{ml}$, adicionar aproximadamente $200 \mathrm{ml}$ de água destilada e ferver por poucos minutos. Deixar esfriar, transferir a solução para um balão volumétrico de $500 \mathrm{ml}$ de capacidade e completar o volume. A solução assim preparada contém 100 e.mg de cálcio por litro. As demais soluções foram preparadas a partir desta, por diluições.

\section{$2.2-$ INSTRUMENTAL}

Espectrofotômetro de chama Beckman, modêlo DU, com adaptações para leitura direta e fonte de alimentação estabilizada para a válvula fotomultiplicadora 1P28. Estas adaptações, originalmente, foram descritas por Brown e colaboradores (4), posteriormente melhoradas por Lott (2) e recentemente publicada com algumas modificações por Coelho ( 7 ), fornecendo voltagem de alimentação para o fototubo vermelho, aumentando a sensibilidade do voltímetro com utilização de válvula de maior ampli-

(2) Engenheiro-Químico, IBEC Research Institute, informaça pessoal. 
ficação e voltagem de placa mais elevada. Além de substituir um conjunto de baterias especiais e estabilizador de voltagem, o uso do voltímetro electrônico de leitura direta proporciona muito maior rendimento analítico e aumento de sensibilidade em relação ao método dos "nulos", utilizado originalmente no espectrofotômetro.

A combinação de gases utilizada na chama foi de hidrogênio e oxigênio, usando o bico atomizador Beckman 4020 .

\section{3 - RESULTADOS E DISCUSSÃO}

\section{1 - PRESSÕES DE OXIGÊNIO E HIDROGÊNIO}

Cada fotômetro de chama possui determinadas características individuais, com as quais o técnico deve familiarizar-se a fim de obter do aparelho a maior eficiência possivel, tanto em sensibilidade como em estabilidade.

O bico atomizador está sujeito a variaçōes individuais, devendo as pressões dos gases que compõem a chama serem ajustadas para cada bico.

A intensidade e estabilidade máximas de emissão do cálcio em chama de oxigênio e hidrogênio foram determinadas, mantendo constante a pressão de oxigênio, em diferentes níveis, e variando a pressão de hidrogênio.

Inicialmente, a câmara de atomização foi pré-aquecida durante cinco minutos, para evitar condensação do aerosol e correspondente instabilidade da chama. Com abertura de janela (slit) de $0,025 \mathrm{~mm}$ e pressão de oxigênio e de hidrogênio de 10 e 5 libras por polegada quadrada, respectivamente, variou-se o comprimento de onda, encontrando a máxima intesidade de cálcio a 428,3 milimicrons, o qual foi utilizado nos estudos posteriores. Em seguida, atomizando uma solução de cálcio 0,002 N e mantendo a pressāo de oxigênio em 10 libras, foram feitas leituras de emissão do cálcio, para as pressões de hidrogênio de $1,0,1,5,2,0,2,5,3,0,3,5,4,0,4,5,5,0$ e 5,5 libras por polegada quadrada. O mesmo foi executado para pressóes de oxigênio de 12, $14,16,18$ e 20 libras por polegada quadrada, obtendo-se os gráficos da figura 1. 


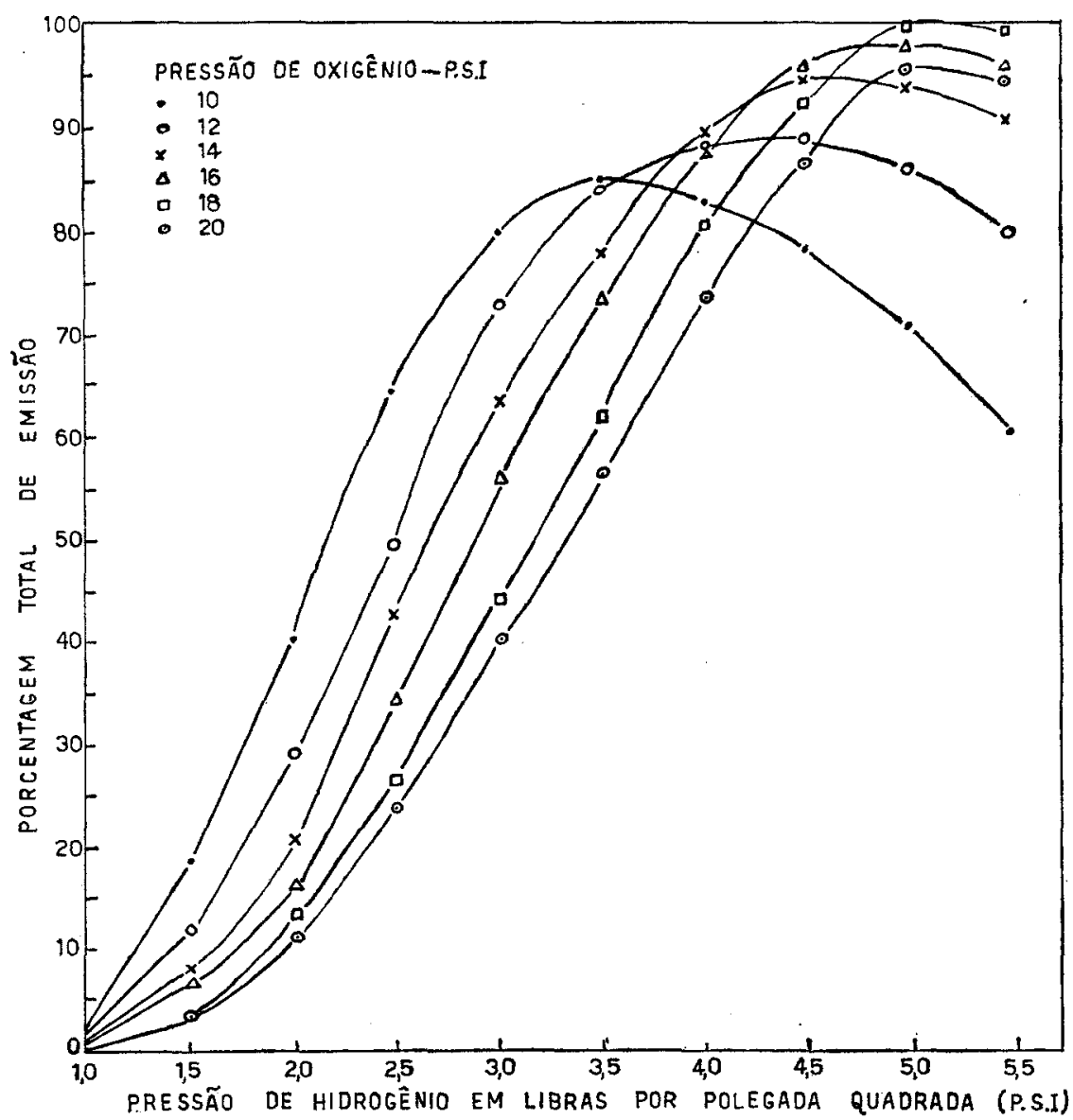

Figura 1. - Efeito da composição de chama (pressōes de oxigênio e hidrogênio) sôbre a estabilidade e emissão de cálcio em solução, em sua determinação espectrofotométrica.

A observação das curvas dessa figura permite o estudo das relações das pressóes dos gases, mostrando que a porcentagem máxima de emissão de cálcio se verificou com pressóes de oxigênio e de hidrogênio, de 18,0 e 5,0 libras por polegada quadrada, respectivamente. Verificou-se ainda que, à medida que a pressão do oxigênio é aumentada e a pressão do hidrogênio é mantida entre 5,0 e 5,5 libras por polegada quadrada, a emissão de cálcio sofre cada vez menores variaçōes. Com a pressão de hidrogênio entre os limites apontados e a do oxigênio a 18, a variação na 
emissão de cálcio foi de $0,7 \%$, enquanto com o oxigênio na pressāo de 10 a variação encontrada foi de $10,8 \%$. Se, no entanto, a pressão do oxigênio fôr de 18 libras por polegada quadrada, as variações da emissão de cálcio provocadas pela mudança na pressão dêsse gás, mantendo constante a pressão do hidrogênio, são bem menores do que com outras pressões daquele gás. P'ela observação dos resultados das variações das pressões, foram adotadas, na condução do presente trabalho, as pressões de 18 e 5 libras por polegada quadrada, para o oxigênio e para o hidrogênio, respectivamente.

\section{2 - CURVA PADRÃO}

Partindo da solução de cálcio a $2.000 \mathrm{ppm}$, foram preparaảas por diluiçōes as soluções de cálcio com concentrações variando entre 0 e $200 \mathrm{ppm}$, com intervalos regulares, entre elas. de $20 \mathrm{ppm}$. Essas soluções correspondem a extratos de solos em teores variáveis de 0 a 10 e.mg de cálcio por $100 \mathrm{~g}$ de solo sêco.

Para a obtenção da curva padrão e de todos os dados dêste trabalho, o espectrofotômetro foi mantido sempre dentro das seguintes características:

Abertura de janela (slit) ... - 0,025 $\mathrm{mm}$

Mistura de gases ......... - oxigênio e hidrogênio

Pressão de $\mathrm{O}_{2}$ no aparelho .. - 18 libras por polegada quadrada Pressão de $\mathrm{H}_{2}$ no aparelho .. - 5 libras por polegada quadrada Comprimento de onda .....-428,3 milimicrons

A figura 2 mostra a curva padrão obtida com a determinação de soluções puras de cálcio.

\section{3 - ESTUDO DAS INTERFERÊNCIAS}

Dentro das concentrações que ocorrem nos extratos de solo, sòmente os ions $\mathrm{PO}_{4}^{-}, \mathrm{Al}+++$ e Fe+t é que apresentam interferências na determinação do cálcio. Para facilidade de exposição passaremos a descrever com detalhe cada uma, individualmente. 


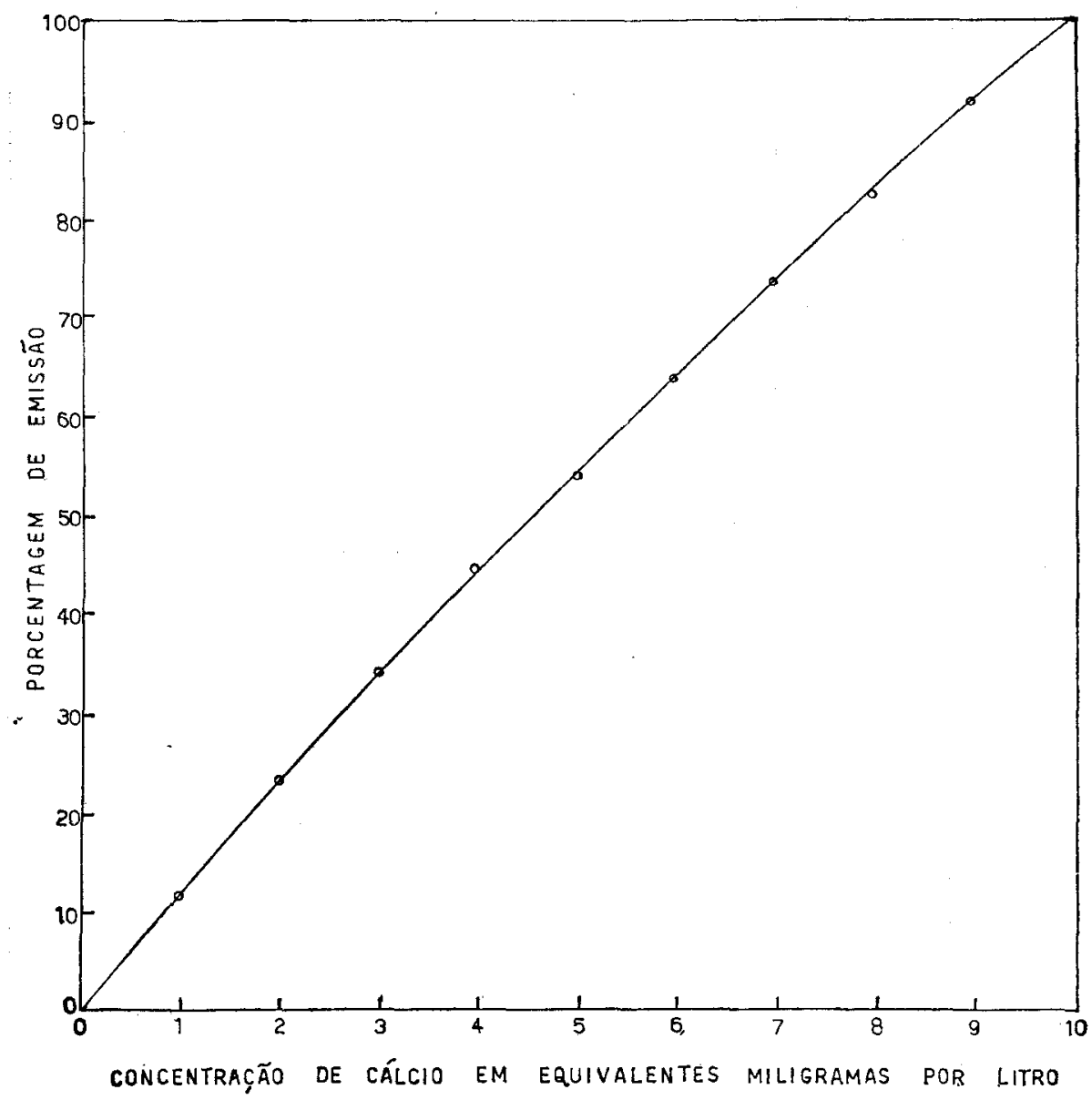

Figura 2. - Curva padrão para determinação de cálcio por fotometria de chama.

\section{3 .1 - ALUMínIO}

O alumínio possui grande interferência na determinação espectrofotogramétrica do cálcio, conforme já observado por diversos autores (20, 23 e 25). Pelos dados do quadro 1, observou-se que êsse íon tem um efeito depressivo diretamente proporcional à sua concentração na solução de cálcio. Estudou-se êsse efeito em solução de cálcio a $40 \mathrm{ppm}$ para níveis de alumínio variando de 10 a $50 \mathrm{ppm}$. Pelos resultados, verificou-se haver necessidade da eliminação da sua interferência nas determinações de cálcio. 
QUAdRo 1. - Efeito da concentração de aluminio sôbre os valores de concentração aparente de cálcio a $40 \mathrm{ppm}$

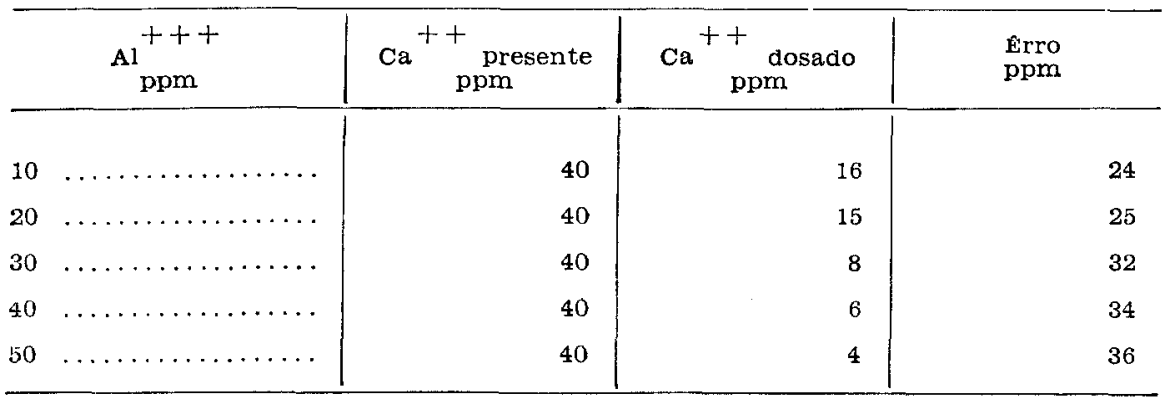

\section{3 .2 - FOSFATO}

O íon fosfato interfere na determinação do cálcio, deprimindo a sua emissão na chama $(1,6,10,11,21,23,25)$. Verificou-se a intensidade da interferência do fosfato em niveis de possiveis ccorrências em extratos de solo, que pode conter de 0,02 a 1,10 e.mg/litro, em soluções de cálcio com concentraçōes de 20 e 40 ppm.

Felos dados obtidos, gràficamente expostos na figura 3 , verificou-se que o ion fosfato inicia a interferir na determinação do cálcio a partir da concentração de 0,10 e.mg/l. Nessa concentração, a depressão encontrada foi de $1,5 \%$, enquanto na concentração de 1,10 e.mg/l o cálcio aparente foi de $55 \% \mathrm{em}$ relação ao realmente presente na solução.

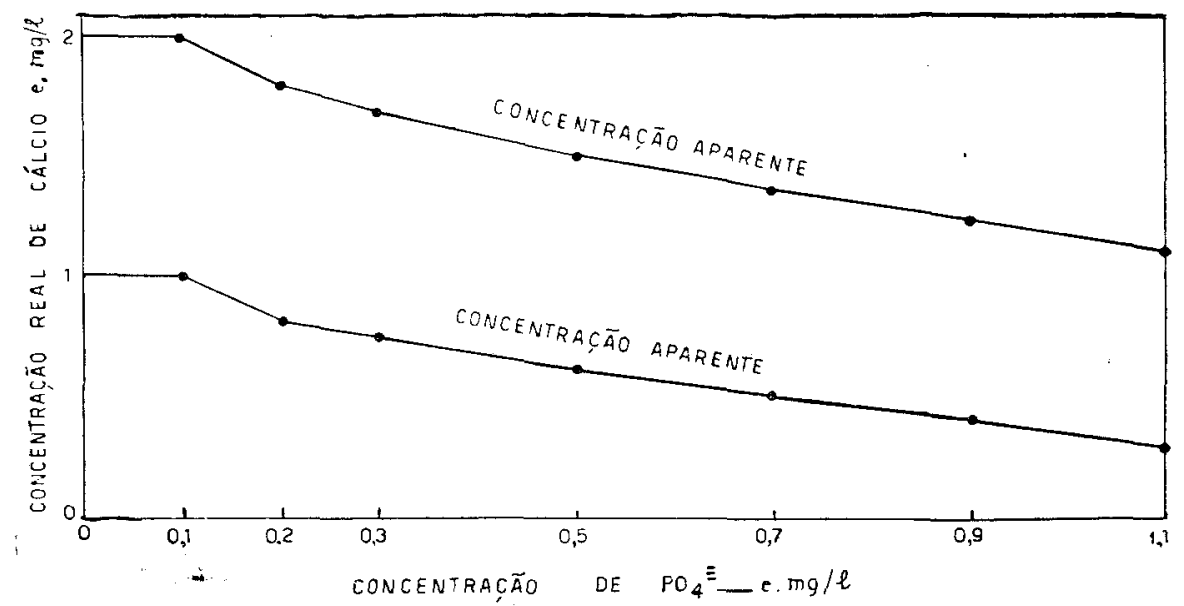

Figura 3. - Efeito depressivo da concentração do anion fosfato, na determinação do cálcio por espectrofotometria de chama. 


\subsection{3 - FERRO $\mathbf{E}$ OUTROS IONS}

Verificou-se que o ferro deprimiu a emissão de cálcio a um valor constante, quando presente na solução em quantidades acima de $5 \mathrm{ppm}$. Numa solução de $40 \mathrm{ppm}$ de cálcio e de 10 a $80 \mathrm{ppm}$ de ferro, o êrro verificado foi de $16 \%$ sòmente.

Outros íons, como manganês, nitrato, sulfato e sódio, não apresentaram interferência alguma, nas concentrações em que normalmente ocorrem nos extratos de solo.

\section{4 - ELIMINAÇÃO DE INTERFERÊNCIAS}

Pelos resultados obtidos neste trabalho, verificou-se que, na determinação do cálcio em extratos de solo, os íons fosfato, aluminio e ferro interferem e constituem problema nessa determinação.

Para eliminação ou redução dessas interferências, nas determinaçōes de cations por espectrofotometria de chamas tem sido utilizado o EDTA, o qual mantém a emissão do elemento em nível constante de intensidade, segundo diversos autores $(10,25,26)$. O princípio de sua ação, é a complexação do cálcio pelo EDTA, que é decomposto na chama, livre portanto das interferências. I linnin (10) recomenda o uso de EDTA 0,01 M na solução de cálcio, a partir de solução de EDTA 0,5 M a pH 9,0. Tendo-se presente que as concentraçōes dos íons interferentes, no extrato de solo, são bastante menores que os estudados por êsse autor, e levando-se em consideração que a concentração do EDTA por Êle utilizada iria trazer problema na análise de cálcio, devido ao excesso de sódio na solução, a concentração de EDTA estudada variou entre $0,005 \mathrm{M}$ e $0,015 \mathrm{M}$, usando-se $5 \mathrm{ml}$ da soluçāo de cálcio que continha $0,05,0,10$ e $0,15 \mathrm{ml}$ de EDTA $0,5 \mathrm{M}$.

No quadro 2, estão arrolados os resultados obtidos com essa técnica, onde foram utilizadas soluçōes de cálcio que continham fosfato, ferro e alumínio, em diferentes concentrações.

Ésses resultados indicam que a concentração de EDTA $0,010 \mathrm{M}$ na solução de cálcio foi eficiente na eliminação de interferências produzidas por fosfato, ferro e alumínio, sendo que o último até à concentração de 1,0 e.mg/litro. 
QUADRO 2. - Eliminação de interferências de $\mathrm{PO}_{4}^{---}, \mathrm{Fe}^{+++}$e $\mathrm{Al}^{+++}$ na determinação espectrofotométrica de cálcio

\begin{tabular}{|c|c|c|c|c|c|}
\hline \multirow{4}{*}{$\begin{array}{l}\text { Teor do íon } \\
\text { interferente }\end{array}$} & \multicolumn{5}{|c|}{ C \& I c i o } \\
\hline & \multirow{3}{*}{$\begin{array}{l}\text { Presente } \\
\text { e.mg/1 }\end{array}$} & \multirow[b]{3}{*}{ Sern EDTA } & \multicolumn{2}{|c|}{ Obtido - e.mg/1 } & \\
\hline & & & \multicolumn{3}{|c|}{ Com EDTA } \\
\hline & & & $0,005 \mathrm{M}$ & $0,010 \mathrm{M}$ & $0,015 \mathrm{M}$ \\
\hline $\mathrm{PO}_{4}^{---}$ & & & & & \\
\hline $0,04 \mathrm{e} . \mathrm{mg} / 1 \ldots$ & 2,00 & 2,00 & 2,00 & 2,00 & 2,00 \\
\hline $9,08 \quad " \quad " \quad, \ldots$ & 2,00 & 2,00 & 2,00 & 2,00 & 2,00 \\
\hline $0,12 " \quad " \quad \cdots$ & 2,00 & 1,96 & 2,00 & 2,00 & 2,00 \\
\hline $0,16 ", \quad, \ldots$ & 2,00 & 1,88 & 2,00 & 2,00 & 2,00 \\
\hline $0,20 " \quad " \quad \ldots$ & 2,00 & 1,80 & 2,00 & 2,00 & 2,00 \\
\hline $0,30 ", " \quad \ldots$ & 2,00 & 1,68 & 1,96 & 2,00 & 2,00 \\
\hline $0,50 " \quad " \quad " \ldots$ & 2,00 & 1,52 & 1,90 & 2,00 & 2,00 \\
\hline $\mathrm{Fe}^{++t}$ & & & & & \\
\hline 5 ppm ... & 2,00 & 1,76 & 2,00 & 2.00 & 2,00 \\
\hline $10 \quad " \quad \ldots$ & 2,00 & 1,76 & 2,00 & 2,00 & 2,00 \\
\hline $20 \quad, \quad \ldots$ & 2,00 & 1,76 & 2,00 & 2,00 & 2,00 \\
\hline $40 " \quad \ldots$ & 2,00 & 1,76 & 2,00 & 2,00 & 2,00 \\
\hline $80 \quad " \quad \ldots \ldots \ldots$ & 2,00 & 1,76 & 2,00 & 2,00 & 2,00 \\
\hline $\mathrm{A}, \mathrm{l}^{++}$ & & & & & \\
\hline 1 e. $\mathrm{mg} / 1 \quad \ldots$ & 2,00 & 0,82 & 1,92 & 1,98 & 1,98 \\
\hline $2 " \quad " \quad " \ldots \ldots$ & 2,00 & 0,78 & 1,48 & 1,86 & 1,90 \\
\hline $3 " \quad " \quad \cdots \ldots \ldots$ & 2,00 & 0,42 & 0,90 & 1,68 & 1,80 \\
\hline $4 " \quad " \quad " \quad \ldots \ldots$ & 2,00 & 0,28 & 0,70 & 1,43 & 1,72 \\
\hline $5 \quad " \quad \cdots \quad " \quad \ldots \ldots$ & 2,00 & 0,24 & 0,56 & 1,28 & 1,60 \\
\hline
\end{tabular}




\section{5 - DETERMINAÇÃo DO CÁLCIO EM EXTRATO DE SOLO}

A determinação espectrofotogramétrica do cálcio foi realizada em extratos com cloreto de potássio normal e com ácido nítrico 0,05 normal, empregando-se técnicas diferentes na eliminação das interferências.

No extrato nítrico, onde a concentração dos íons interferentes é relativamente alta, utilizou-se a adição de EDTA, em diferentes concentrações.

No extrato com cloreto de potássio, como a concentração salina é elevada e iria danificar o bico atomizador, além da grande interferência do potássio na emissão do cálcio, os extratos foram diluídos 5 vêzes com água destilada. As curvas padrōes foram feitas a partir de soluções padrões de cálcio, nas quais se adicionou EDTA ou cloreto de potássio, conforme o extrato, de modo a fornecer concentrações idênticas, dêsses sais, ao dos extratos utilizados.

Paralelamente, como referência, procedeu-se a determinação do cálcio nos extratos, pelo método do EDTA (22).

Pelos dados do quadro 3, verificou-se que os dois processos estudados revelaram-se satisfatórios, e o EDTA mostrou-se eficiente na eliminação das interferências.

\section{4 - CONCLUSÕES}

Os resultados permitem as seguintes conclusões:

a) Os íons fosfato, ferro e alumínio interferiram sobremaneira na determinação do cálcio por fotometria de chama.

b) Para a determinação do cálcio em extratos de solo, houve necessidade de eliminar as interferências dêsses três ions.

c) A utilização do EDTA foi altamente eficiente na eliminação das interferências na determinação do cálcio por fotometria de chama. 


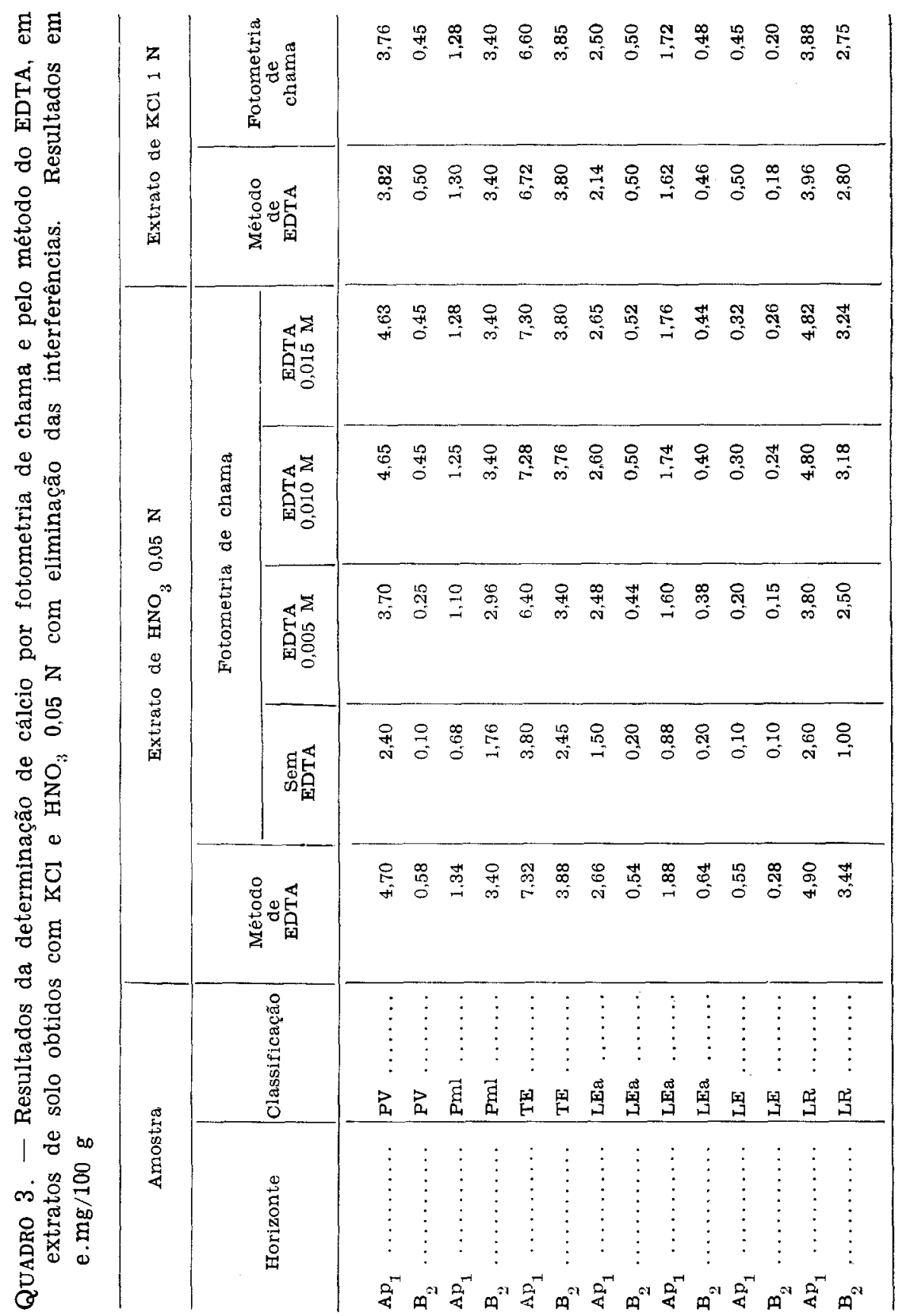


SPECTROPHOTOMETRIC DETERMINATION OF CALCIUM IN SOILS

\section{SUMMARY}

A study is presented on the determination of calcium in soil extracts by flame photometry, using a Beckman Model DU spectrophotometer.

Flame composition, gas pressure, interferences and their elimination were studied.

Results showed it to be necessary to eliminate interferences due to aluminum, iron and phosphate ions in amounts normally present in soils.

Enough EDTA solution at pH 9.0 was added to the soil extract until a concentration of $0.01 \mathrm{M}$ in EDTA was reached.

\section{LITERATURA CITADA}

1. BAKER, G. L. \& JOHNSON, L. H. Effects of anions on calcium flame emission in flame photometry. Analyt. Chem. 26:465-468, 1954.

2. BROWN, J. G.; LILLELAND, O. \& SACKSON, R. K. The determination of calcium and magnesium in leaves using flame methods and quartz spectrophotometer. Proc. Amer. Soc. hort. Sci. $52: 1-6,1948$.

3.

use of flame methods for the analysis of plant material for potassium, calcium, magnesium and sodium. Proc. Amer. Soc. hort. Sci. 56:12-22, 1950.

4. — \& PATTERN, C. G. Rapid determination of potassium and magnesium by flame photometry. Proc. Amer. Soc. hort. Sci. 39:337-342, 1952.

5. BRYAN, H. A. \& DEAN, S. A. Extration and flame spectrophotometric determination of chromium. Analyt. Chem. 29:1289-1292, 1957.

6. CHEN JR., P. S. \& TORIBARA, T. Y. Determination of calcium in biological material by flame photometry. Analyt. Chem. 25:1642-1644, 1953.

7. COELHO, FERNANDO A. S. Complementos para o espectrofotômetro de chama Beckman modêlo DU. Antenna 59:202-205, 1968.

8. DAVID, D. J. Determination of calcium in plant material by atomic-absorption spectrophotometry. Analyst 84:536-545, 1959.

9. DEAN, J. A. \& CAIN JR., C. Flame spectrophotometric determination of copper, nickel and manganese in aluminium alloys. Analyt. Chem. 29:530-532, 1957.

10. DINNIN, J. I. Realising effects in flame photometry. Analyt. Chem. 32:1457-1480, 1960. 
Vol. 28, N. ${ }^{\circ} 20$

11. FIELDS, M. et alii. Estimation of exchangeable cations in soils, with the Beckman flame spectrophotometer. Soil Sci. 72:219-232, 1951.

12. FOSTER JR., W. H. \& HUME, D, N. Mutual cation interference effects in flamephotometry. Analyt. Chem. 31:2033-2036, 1959.

13. GALLO, J. R.; ALVAREZ, R. \& ABRAMIDES, E. Amostragem em cana-de-açúcar para fins de análise foliar. Bragantia $21: 899-922,1962$.

14.

\& MIYASAKA, S. Composição química do feijoeiro e absorção de elementos nutritivos do florescimento à maturação. Bragantia 20:867-884, 1961.

15. \& OLIVEIRA, A. S. DE. Variações sazonais na composição mineral de fôlhas de videira e efeitos do porta-enxêrto e da presença de frutos. Bragantia 19:883-889, 1960.

16. \& RODRIGUES, O. Efeitos de algumas práticas de cultivo do solo, na nutrição mineral dos citros. Bragantia $19: 345-360,1960$.

17. GARGaNTINI, H.; BLANCO, H. G.; GALLO, J. A. \& NóBREGA, S. A. Absorção de nutrientes pela batatinha. Bragantia 22:267-290, 1963.

18. HEMINGWAY, R. G. The determination of calcium in plant material by flame photometry. Analyst 81:164-168, 1956.

19. LOTT, W. L. et alii. Levantamento de cafezais em São Paulo e Paraná pela análise foliar. São Paulo, IBEC Research Institute, 1961. 72p. (Boletim 26)

20. MOSHER, R. E.; BIRD, E. J. \& BOYLE, A. J. Flame photometric determination of calcium in brucite and magnesite. Analyt. Chem. 22:715-717, 1950.

21. PIETZKA, G. \& CHUN, H. Flammenphotometrie, I. Angew Chem. $71: 276-283,1959$.

22. RAIJ, BERNARDO VAN. Determinação de cálcio e magnésio pelo EDTA em extratos ácidos de solos. Bragantia: 25:317-326, 1966

23. SHAW, W. M. \& VEAL, N. C. Flame photometric determination of exchangeable calcium and magnesium in soils. Proc. Soil. Sci. Soc. Am. 20:328-333, 1956.

24. TOTH, S. J. \& PRINCE, A. L. Estimation of cation exchange capacity and exchangeable calcium, potassium and sodium contents of soil by flame photometer techniques. Soil Sci. $67: 439-445,1949$.

25. WEST, A. C. \& COOKE, W. D. Elimination of anion interferences in flame spectroscopy use of (ethylene dinitro) Tetraacetil acid. Analyt. Chem. 32:1471-1474, 1960.

26. WIRTSCHAFTER, J. D. Supression of radiation interference in flame photometry by protective chelation. Science 25:603-604, 1957. 